\title{
THE PRINCIPLES OF ENVIRONMENTAL PROGRAM FORMATION FOR DISTRICT PLANNING
}

\author{
Andrey Leonidovich Pozdnyakov \\ Southwest State University, Faculty of Building and Architecture, Kursk, Russia
}

On mesoterritorial level (schemes and projects of district planning) urban structures are studied and designed with much more detail, and because of the greater complexity of district planning spectrum of relationships between natural and anthropogenic components of the district is particularly rich. Therefore, urboecological tasks at this level include not only the special zoning of the territory, but the development of quite specific environmental and hygienic measures, including proposals for the establishment of systems for purification of air, water and soil, the allocation of the various security and sanitary protection zones, the development of green plantings of district, etc. At the same time, geographic, ecological and architectural-planning methods as well as technological and hygienic ones are equally applicable.

Key words: Ecology, District planning, Environmental program

\section{INTRODUCTION}

Schemes and projects of the district planning on the basis of the program-target approach, their complexity and concreteness in comparison with the schemes of regional settlement allow us to consider issues of the interaction between the settlement and the environment not only in more detail, but also taking into account the impact of other constructive tasks of the regional planning on them - the development and the location of industry, agriculture and forestry, the formation of engineering and technical infrastructure, etc.

Within the framework of the district planning as a complex of technical, economic, planning and engineering measures the study of nature management issues and their constructive solution, including environmental protection, becomes a broad task related to the deployment of productive forces, resettlement, and the organization of mass recreation of people. Sufficiently effective implementation of any task of the district planning to some extent involves the implementation of environmental measures.

Especially important is the protection of the environment in solving the problems of resettlement, which in itself is inconceivable without creating the best possible conditions for human life. At the same time, it has already been noted above that the depth, validity and degree of complexity of nature protection issues in the schemes and projects of the district planning currently being developed does not already meet the new requirements that the scientific and technological revolution engenders. In these conditions, the most important is the development of the methodology of the regional planning not only on the basis of the strengthening of traditional territorial and integrated in it, the introduction of systemic and bioeconomic approaches, the broad development of urban-ecological studies within it, but also a signifi- cant change in the methodology of the regional planning based on the program-target approach, including the development of environmental programming in it.

It was mentioned above that the ideas of system analysis, including the program-target approach, were used in solving scientific and constructive problems in town planning and in particular with regard to the formation of group systems of populated areas [01]. There are known attempts to apply methods of system analysis to district planning in general. Based on the work on the general methodology of system analysis, on the application of the system approach in town planning, and also taking into account the specificity of the area - the object of planning as a complex polystructural bioeconomic system, a technological scheme of the regional planning was developed on the basis of system analysis, including several successive stages [02].

\section{DETERMINATION OF MAIN AND DERIVATIVE GOALS OF TERRITORY DEVELOPMENT}

As goals of the first level, it is necessary to take strategic tasks of territory development, urban development, infrastructure, preservation and improvement of the environment. The starting points for selecting goals for this level should serve the goals set in the scheme for locating the productive forces, economic regions, the scheme of resettlement in the country and in the regions.

The objectives of the first level are divided into the objectives of the second and, if necessary, the third level (constructive tasks) in relation to the specific conditions of the region in question, resulting in a tree of goals ranked by their importance and sufficient for the development of general directions for the development of the area.

Analysis of the resources needed to achieve the set goals. 
This part of the work includes the analysis of natural conditions, labor, material and other resources (renewable and nonrenewable), the degree of resource availability of the district is determined, taking into account the forecast data. Here, an analysis and a comprehensive assessment of the area is carried out.

Analysis of the main problems of the development of the region, taking into account the achievements of scientific and technical and social progress. The economic and demographic capacity and the reproductive capacity of the district are determined from the positions of the targets and the resources identified.

Formation of the main directions of the development of the district - its economy, urban development, infrastructure, the state of the environment, as well as the definition of the main relations of the most important national economic sectors, general indicators of the prospective population, industrial and agricultural production, etc. At the same stage, preliminary coordination of the main goals and resources is carried out [03].

Development of mutually exclusive alternatives for the development of the district (taking into account the achievement of the set goals), including functional zoning, planning structure, various ways of achieving ecological balance.

\section{COMPLEX SOCIAL-ECONOMIC, PLANNING AND ECOLOGICAL EVALUATION OF ALTERNATIVES AND CHOICE OF THE MOST ACCEPTABLE SOLUTION}

Development of integrated interrelated socio-economic and environmental programs based on the chosen alternative.

The development of complex programs is the most difficult and time-consuming part of the work. It is here that the final alignment of the goals and resources of each program is carried out, their options are compared and selected, taking into account the achievement of the greatest effect of the system as a whole. Since the objectives of each program reflect the most important goals of another program, the achievement of which can be regarded as a certain limitation for the optimal performance of the main program, a repeated revision of the development programs of the subsystems is inevitable through a series of successive iterations.

The best version of the programs, linked to the goals and resources and most effective for the system as a whole, is adopted as the main one and is included in the final stage of the work.

Design of a synthesizing project plan of the district, in which long-term programs for the development of individual subsystems receive the necessary territorial linkage. Here, a prospective land balance is not drawn up [04].

These stages reflect the possible development of schemes and projects of the district planning. In this case, the goals, methods of analysis, forecasting and synthesis will, of course, differ significantly in specific situations. The above simplified logical model indicates the great complexity of the process of developing schemes and projects of district planning based on system analysis. Since the main task of this process is the development of integrated programs and subprograms for the development of individual subsystems of the district, the participation of industry institutes, the development of a unified methodology for integrated programming and criteria for program evaluation, is of paramount importance in their compilation. At the same time, the most complete integration of long-term programming processes and the inclusion of district planning in the system of socio-economic planning of the country, its individual regions, act as the main organizational task of the district planning [05].

Composition and content of the program. The environmental program (or program for environmental protection and improvement), as well as the socio-economic program, which is a subprogram of the corresponding programs of a higher territorial level, should be based on the following main principles:

- methodology of system analysis, and first of all the program-target approach;

- taking into account exogenous factors, that is, being linked to the objectives of similar programs of a higher territorial level;

- taking into account endogenous conditions, that is not to enter into significant contradictions with the capabilities, resources and planning objectives of the area in question;

- taking into account the main objectives of the related program, which in some cases may act as external constraints [06].

The ecological program of the scheme or project of the district planning, its structure, content, etc., may have certain differences depending on the type of district planning, economic and environmental conditions of the area, its economic and geographical situation. However, any such program should contain the main sections, the implementation of which can contribute to the implementation of a system of measures to maintain the ecological balance in a particular area.

In general, the environmental program should include the following sections, which are developed, as a rule, simultaneously and in conjunction with other programs of the district planning:

- general ecological character of the area (comparative analysis of the state of the environment, determination of the demographic capacity of the territory, urboecological characteristics - reproductive capacity, geochemical activity and ecological capacity of the territory); 
- protection of soil and vegetation cover, restoration of disturbed lands (analysis and forecast of the state of soil and vegetation cover, measures aimed at protecting soil and vegetation from erosion, trampling, pesticide contamination, at creating a system for removing and eliminating debris and recultivation of disturbed territories, etc.);

- protection of the air basin (natural and anthropogenic prerequisites for atmospheric air pollution, analysis and forecast of the air basin state, proposals for maintaining the frequency of the air basin, etc.);

- protection of the water basin (natural and anthropogenic prerequisites for surface and groundwater pollution, analysis and forecast of the state of the water basin, proposals for ensuring the cleanliness of the water basin, etc.);

- protection of the animal world (development of biotechnical and general planning activities that contribute to the identification and preservation of rare and valuable animals in an economical way, etc.);

- improvement of sanitary and epidemiological conditions (identification of foci of epidemiological and endemic diseases, development of measures to eliminate these diseases, etc.);

- protection of the environment from noise, electromagnetic vibrations, heat pollution and radiation (development of proposals for the organization of anti-noise and other protection zones, placement of industrial and other facilities, taking into account specific conditions, etc.);

- formation of a unified system of green plantations of the area (establishment of the minimum permissible and optimal forest cover, the size and configuration of green plantations, proposals for the formation of interrelated elements of the natural framework - forests and other plantations of various functional purposes);

- protection of historical and cultural monuments (identification, systematization and development of proposals for the use and protection of architectural, historical, ethnographic and other monuments with their natural environment);

- formation of a system of protected areas (national and natural parks, reserves, protected landscapes, individual objects of living and inanimate nature, etc.);

- protection and improvement of the landscape (conservation, enrichment and purposeful formation of the appearance of natural and anthropogenic landscapes, reclamation of the territory, measures to improve the aesthetic qualities of landscapes, etc.);

- compilation of a comprehensive scheme for environmental protection of the district (urboecological zoning of the territory, spatial localization of environmental measures, etc.);
- determination of the effectiveness of environmental measures and ways to implement them.

The environmental program has many stages that can be grouped into three main stages - analytical, prognostic and synthesizing.

The analytical stage is largely based on an assessment of the natural conditions, resources and territory of the area under consideration, performed at the very beginning of the development of the scheme or the project of the district planning. It includes a general analysis of the urban ecological characteristics, as well as an exploratory analysis of the quantitative, qualitative and hygienic state of the most important components of the environment - water, air, soil and vegetation, and identification of existing disproportions in the relationship between the natural and anthropogenic subsystems. The analysis of the sanitary state of the air and water basins of the district - the object of the regional planning, the degree of pollution and erosion of the soil cover, the state of valuable and unique natural landscapes, the degree of disturbance of the territory by mine workings and the spreading of unsuitable lands - is of great importance here. Deviations from the permissible loads on the landscape, MPC and MPE should be determined, zones with different degrees of pollution, the extent of inappropriate development of the coastal strip, the area of construction of valuable natural landscapes, etc. should be established [07]. The results of the analysis should serve as the initial basis for determining the main directions for the purposeful evolution of the natural environment of the area and for clarifying the goals and resources (taking into account the goals and resources of the corresponding program of a higher territorial level) necessary for the development of an environmental program.

The prognostic stage is the most complex and least developed in theoretical and practical terms part of the environmental program. Its task is to determine the expected state of the natural environment in the long term, taking into account the goals set in the program and the constructive tasks aimed at achieving ecological balance in the area. There are many methods of forecasting, including those applicable to the promising state of the environment, but not all of them are fairly simple for district planning as a project discipline. Therefore, the forecast should be based mainly on comparing the results of the analysis with the expected changes in the state of the air, water basins, soil and vegetation cover of the area that are unavoidable due to the development of the economy, urban development, social and technical infrastructure on its territory. Criteria for achieving the constructive goals of the environmental program should be regulations and standards for nature protection, as well as hygienic standards [08].

It is very important when forecasting to take into account not only possible achievements in the field of wastewater and air purification, changes in the technological cycles of industrial production, advanced methods of agriculture 
and forestry related to scientific and technical and social progress, but also less optimistic options, which will allow more flexible approach to the adoption of planning decisions and ensure the system as a whole the necessary reliability.

The synthesizing stage of the environmental program includes both recommendations on urban environmental zoning, the development of a system of measures for air and water purification, preservation of soil and vegetation cover, and the development of the main graphic document - a comprehensive scheme for environmental protection.

Similar stages with the corresponding constructive content should be developed for even more detailed stages of town planning design - projects of detailed planning of industrial and residential areas and projects for building microdistricts and urban complexes.

\section{CONCLUSION}

The methodological procedures of the ecological block of regional settlement and the ecological program of the regional planning - the development of analytical, prognostic and synthesizing stages, mathematical modeling with the use of various computer programs and other specialized methods - contribute to a comprehensive consideration of not only ecological but also social and economic development problems of a particular region. They allow us to reveal quite thoroughly and deeply the most significant interrelationships in the "settlement-environment" system, to develop on a new ecological basis a very effective system of measures for the protection of air and water basins, soil and vegetation, animals, historical and cultural monuments, the formation of a system protected areas, to protect the environment from noise, electromagnetic vibrations, thermal and radioactive contamination, improve the aesthetic properties of the landscape, while providing good conditions for work, life and rest of the population.

\section{ACKNOWLEDGEMENT}

Author thanks the Rector of the Southwest State University, Doctor of Technical Sciences Yemelyanov S.G.

\section{REFERENCES}

1. Kochetkov A.V. (1975) The system of urban development management goals and population systems: The use of applied system analysis in the design and management of urban development, pp. 36-54.

2. Kochetkov A.V., Ronkin G.S. (1974) Methodology for the development of complex formation programs and developed group settlement systems: Forecasting the development of a network of populated areas, pp. 30-49.

3. Kochetkov A.V., Listengurth F.M. (1974) A systematic approach to forecasting the development of a network of populated areas: Forecasting the development of a network of populated areas, pp. 5-23.

4. Demin N.M., Lavrik G.I. (1975) Methodological basis of the district planning, $96 \mathrm{p}$.

5. Pozdnyakov A.L., Zvyagintseva M.M. (2017) General problems of the interdependent development of the biosphere and urbanized environment: Journal of Applied Engineering Science, No. 15/3, pp. 292-297.

6. Percik E.N. (1973) District planning, 270 p.

7. Vladimirov V.V. (1976) District planning and systems approach: District planning, pp. 5-18.

8. Kochetkov A.V., Vladimirov V.V. (1977) Accounting for the requirements for the preservation and improvement of the environment in the formation of systems of populated areas: Town-planning, pp. 3-6. 